\title{
The Role of Environmental Contamination in the Transmission of Nosocomial Pathogens and Healthcare-Associated Infections
}

\author{
Geehan Suleyman $^{1} \cdot$ George Alangaden $^{2} \cdot$ Ana Cecilia Bardossy $^{2}$ \\ Published online: 27 April 2018 \\ (C) Springer Science+Business Media, LLC, part of Springer Nature 2018
}

\begin{abstract}
Purpose of Review The aim of this review is to highlight the role of environmental contamination in healthcare-associated infections (HAIs) and to discuss the most commonly implicated nosocomial pathogens.

Recent Findings Recent studies suggest that environmental contamination plays a significant role in HAIs and in the unrecognized transmission of nosocomial pathogens during outbreaks, as well as ongoing sporadic transmission. Several pathogens can persist in the environment for extended periods and serve as vehicles of transmission and dissemination in the hospital setting. Cross-transmission of these pathogens can occur via hands of healthcare workers, who become contaminated directly from patient contact or indirectly by touching contaminated environmental surfaces. Less commonly, a patient could become colonized by direct contact with a contaminated environmental surface.

Summary This review describes the role of environmental contamination in HAIs and provides context for reinforcing the importance of hand hygiene and environmental decontamination for the prevention and control of HAIs.
\end{abstract}

Keywords Hospital environment · Environmental contamination · Healthcare-associated infections · Multi-drug resistant organisms $\cdot$ Nosocomial pathogens

\section{Introduction}

Healthcare-associated infections (HAIs) are an important cause of morbidity and mortality in hospitalized patients [1]. Multiple recent studies suggest that environmental contamination plays an important role in the nosocomial transmission of multi-drug-resistant organisms (MDROs), virus, mycobacteria, and fungi [2-5]. Several nosocomial pathogens, including vancomycin-resistant enterococci (VRE), methicillin-resistant Staphylococcus aureus (MRSA), Acinetobacter baumannii, Clostridium difficile, and Pseudomonas aeruginosa, have been shown to persist in the

This article is part of the Topical Collection on Healthcare Associated Infections

Ana Cecilia Bardossy

cbardos1@hfhs.org; cecibardossy@gmail.com

1 Department of Infectious Disease, University of Toledo Medical Center, Toledo, $\mathrm{OH}$, USA

2 Division of Infectious Diseases, Henry Ford Health System, 2799 West Grand Blvd CFP3, Detroit, MI 48202, USA environment for an extended period of time [2, 6-8]. The persistence of these microorganisms in the environment can serve as a source of transmission and dissemination in the hospital environment [9].

This article will review the current epidemiology of common HAIs associated with environmental contamination. The definition of the hospital environment and the role of the contaminated hospital environment, including surfaces, fomites, air, and water, that can serve as potential reservoirs for common nosocomial pathogens associated with HAIs, will be described.

\section{Hospital Environment}

Environment of care is comprised of three elements: the building or space that is used for providing patient care; equipment used to support patient care or to safely operate the building or space; and people, including staff, patients, and visitors [10].

Patient environment is defined as the immediate space around a patient that may be touched by the patient and healthcare worker $(\mathrm{HCW})$ when providing care. In acute care, 
the patient environment is defined as the area inside the curtain, including equipment, medical devices, furniture, telephone, personal belongings, and the bathroom. In intensive care units (ICUs), the patient environment is the room or bed space and items and equipment inside the room or bed space. In a multi-bedroom, this consists of the area inside the individual's curtain [11].

Patients shed microorganisms that can survive for prolonged periods of time in the healthcare environment and can be detected in the air, water, and on surfaces [11]. The number and types of microorganisms present in the environment are influenced by the number of people in that environment, degree of activity, amount of moisture, presence of material capable of supporting microbial growth, rate at which organisms suspended in air are removed, and the type of surface and its orientation (i.e., horizontal or vertical) [12]. Grampositive (GP) organisms generally persist in dry conditions on dust and surfaces $[7,12]$. On the other hand, gram-negative (GN) organisms grow and persist in moist, soiled environments. Fungi thrive in moist, fibrous material but can survive on dust [12].

Construction, renovation, repair, and remediation, such as installing wiring for new information systems, removing old sinks, and repairing elevator shafts, disrupt the environment and expose susceptible patients to microorganisms that contaminate the air, water, and surfaces. Other means of introducing environmental pathogens to high-risk patient areas include using aging equipment, deferred maintenance, and natural disasters $[12,13]$.

Although microbiologically contaminated air, water, and fomites can serve as vehicles of transmission, demonstrating their contribution to infection and disease is difficult $[3,11$, 12]. For an infection to ensue, there has to be a sufficient quantity of a virulent pathogenic organism on surfaces in the environment that is transmitted through the correct portal of entry into a susceptible host [12]. The wider use of more aggressive modalities of treatments, such as stem cell or solid organ transplantation and new chemotherapeutic and immunomodulatory agents, has increased the population of immunocompromised patients at risk of acquiring opportunistic HAIs resulting from environmental contamination with nosocomial pathogens. [14].

\section{Environmental Surfaces}

Environmental surfaces are defined as surfaces that do not come into direct contact with patients during care [12]. Environmental surfaces are divided into two parts: medical equipment surfaces, such as knobs or handles on hemodialysis machines, $\mathrm{x}$-ray machines, and instrument carts; and housekeeping surfaces such as floors, walls, and tabletops [12].

Housekeeping surfaces are further divided into those with frequent hand contact or "high-touch" surfaces and those with minimal hand contact or "low-touch" surfaces. High-touch surfaces include doorknobs, bedrails, light switches, surfaces in and around toilets in patient rooms, and edges of privacy curtains. Low-touch surfaces include walls, ceilings, mirrors, window sills, and flooring in patient-care area $[4,12]$. Huslage et al. quantitatively defined high-touch surfaces based on frequency of HCW contact with surfaces in a patient's immediate environment as the bed rails, bed surface, supply cart, overbed table, and intravenous pumps [4]. High-touch surfaces in close proximity to patients provide the biggest risk of HAI transmission $[4,15,16]$. Similarly, critical and noncritical surfaces have also been used to describe high-and low-touch environmental surfaces, respectively [2].

Environmental surfaces, objects, and medical devices, including blood pressure cuffs, stethoscopes, electronic thermometers, infusion pumps, and hemodialysis machines, can serve as potential reservoirs for nosocomial pathogens that can be transmitted by the hands of HCWs to patients in the absence of adequate hand hygiene [4, 12]. Cross-transmission via the hands of HCWs, who either become contaminated directly from patient contact or indirectly by touching contaminated environmental surfaces, has been implicated in 20 to $40 \%$ of HAIs $[1,13]$. Less commonly, a patient may become colonized by direct contact with a contaminated environmental surface $[1,17,18]$. Although floors are heavily contaminated with $C$. difficile and MDROs, including VRE and MRSA, and come in contact with high-touch objects, they are underappreciated sources of transmission of nosocomial pathogens $[19 \cdot, 20]$.

Doctors' stethoscopes remain a likely source of contamination for various pathogens [2,21], and evidence suggests that bacteria can transfer from the skin to the stethoscope and vice versa [21]. Although the majority of organisms are non-pathogenic, potential pathogens, such as MRSA, Pseudomonas, VRE, and $C$. difficile, have also been isolated. However, a link between contaminated stethoscopes and HAIs has not been established to date [21]. Mobile communication devices can also serve as reservoirs for nosocomial pathogens [22, 23]; however, their role in transmission is undefined. Not surprisingly, Chen et al. demonstrated that medical charts, especially in medical, surgical, and pediatric ICUs, are highly contaminated with bacteria and potential sources of infection [24].

\section{Air-borne Contamination}

Disturbance of soil, water, dust, or decaying material during construction releases microorganisms into the air, which can result in a variety of airborne infections in susceptible hosts if not contained and removed [12, 13]. Exposure to airborne pathogens can cause respiratory infections directly or indirectly. Direct transmission involves exposure to aerosolized droplets from oral or nasal secretions in infected individuals. These infectious particles are generally $>5 \mu \mathrm{m}$ in size and can travel 
up to $3 \mathrm{ft}$ but tend to fall out of the air quickly. Pathogenic microorganisms that can be spread via droplets are influenza virus, rhinoviruses, adenoviruses, and respiratory syncytial virus. Indirect transmission involves the spread of airborne infections via droplet nuclei or residuals of droplets. When suspended in air, droplets desiccate and produce droplet nuclei or particles ranging from 1 to $5 \mu \mathrm{m}$ in size that contain potentially viable microorganisms, remain suspended in air indefinitely, and are dispersed over long distances by air currents [12]. Examples of pathogens that can be spread via droplet nuclei include Mycobacterium tuberculosis, varicella-zoster virus, measles virus, and smallpox virus. The spores of Aspergillus spp., which resist desiccation, have a diameter of 2-3.5 $\mu \mathrm{m}$, can remain airborne indefinitely, and travel long distance [12].

\section{Water-Based Contamination}

Moist environments and aqueous solutions in healthcare setting can potentially serve as reservoirs for water-based and water-borne microorganisms [25]. Water-based pathogens, otherwise known as opportunistic premise plumbing pathogens (OPPPs), naturally inhabit water and grow in water systems. Legionella spp., Pseudomonas, Acinetobacter, Aspergillus spp., and nontuberculous mycobacteria (NTM) are a few examples. On the other hand, water-borne pathogens, such as coliforms, are transmitted by water after fecal contamination [25]. OPPPs are found in low numbers and are associated with biofilms and free-living amoeba that protect them from disinfecting biocides in the water system [12,25]. Stojek et al. demonstrated that $79 \%$ of water samples collected from six hospitals were contaminated with GN organisms [26]. Municipal potable water supplied to the healthcare facility is distributed through an extensive network of plumbing to fixtures, such as handwashing stations, ice machines, and medical equipment. This complex distribution system along with the stagnant water in the network can promote the development of biofilm [3, 13, 27]. Moreover, construction or renovation and increased usage of the water utility systems can release contaminants into the water delivery network by disrupting the biofilm, leading to transmission of waterbased pathogens to susceptible hosts [3, 13, 25]. Furthermore, leakage or condensation of water from pipes can collect on surfaces and cause dampness in building materials, which promote the growth of fungi and bacteria [25].

Patients may become exposed to these pathogens through direct (hydrotherapy) and indirect contact (improperly reprocessed medical devices), ingestion and aspiration of contaminated water, and inhalation of aerosols dispersed from water sources [28]. The first four modes are commonly associated with GN bacteria and NTM. Acinetobacter spp. can proliferate in moist environment and are associated with multiple modes of transmission. Direct inhalation of aerosols generated from showers and faucets may potentially expose patients to Legionella and other GN bacteria such as Pseudomonas [12]. Studies have implicated multiple organisms, including Legionella, Pseudomonas, Aeromonas, Burkholderia, Acinetobacter, extended-spectrum $\beta$-lactamase (ESBL)-producing and carbapenem-resistant Enterobacteriaeae, Aspergillus, and NTM with transmission of HAIs via hospital water [28]. Moreover, flooding has resulted in HAIs due to MDR GN organisms, coliforms, Legionella, NTM, and environmental molds [29]. Recent studies have implicated electronic faucets as reservoirs for Legionella and Pseudomonas [30-32], decorative water wall fountains for Legionella [33, 34], and heater-cooler units (HCU) used in cardiac surgeries for Mycobacterium chimaera $[35,36 \bullet \cdot$.

\section{Hospital Environment Microorganisms and Nosocomial Infections}

Several nosocomial pathogens, including VRE, MRSA, Acinetobacter, C. difficile, and Pseudomonas, have been shown to persist in the environment for several hours, days, or months [2,7] and on HCW hands for hours [3] with endospores typically lasting longer than vegetative bacteria [8]. These microorganisms characteristically survive for long periods after being shed into the environment and are difficult to eradicate [5]. Various microbiologic studies have confirmed that certain nosocomial pathogens can survive for extended periods (Table 1). The hospital environment has been increasingly linked to acquisition of organisms, especially $C$. difficile and MDROs [3]. In a prospective microbiological survey, $40 \%$ of rooms were contaminated with MDROs [16]. Despite terminal cleaning, $\mathrm{Hu}$ et al. demonstrated that biofilms containing MDROs are found on 52\% of ICU surfaces, half of which were SA [44]. Additionally, other studies have demonstrated the transfer of pathogens from surfaces to the hands of HCWs in the absence of direct patient contact [5]. Strain type and conditions such as humidity, temperature, inoculum size, and surface type affect the duration of the persistence $[7,45,46]$.

Epidemiologic studies have also shown that patients admitted to rooms previously occupied by individuals infected or colonized with MRSA, VRE, C. difficile, MDR Acinetobacter, and Pseudomonas are up to a three-fold higher risk of acquiring these organisms from contaminated environmental surfaces [1, 3, 4, 47]. As such, Nseir et al. showed that patients admitted to an ICU room that was previously been occupied by a patient with MDR Pseudomonas or Acinetobacter have an independent risk factor for the acquisition of these bacteria. However, the same was not demonstrated for ESBL-producing GN bacteria [48]. In a recent metaanalysis, Mitchell et al. reported a pooled odds ratio of 2.14 
Table 1 Survival times of nosocomial pathogens on environmental surfaces

\begin{tabular}{|c|c|c|c|}
\hline Organisms & Types of environmental surfaces & Survival time & References \\
\hline \multirow[t]{4}{*}{ Staphylococcus aureus, including MRSA } & Dry inanimate surfaces & 7 days to 5 years & {$[5,7,8,37,38]$} \\
\hline & $\begin{array}{l}\text { Cotton fabric, synthetic fibers, ceramic floor with the } \\
\text { presence of blood }\end{array}$ & 60 to 72 days & [39] \\
\hline & $\begin{array}{l}\text { Ceramic floor, cotton fabric synthetic fibers, eggcrate } \\
\text { foam mattress (with/without biological fluids) }\end{array}$ & $>70$ days & [9] \\
\hline & Office paper & $72 \mathrm{~h}$ to 7 days & {$[40]$} \\
\hline Staphylococcus aureus, vancomycin-intermediate & Vinyl flooring and smooth surfaces & $>45$ days & [41] \\
\hline \multirow[t]{3}{*}{ Enterococcus spp., including VRE } & Dry inanimate surfaces & 5 days up to 5 years & {$[5,7,8,42,43]$} \\
\hline & $\begin{array}{l}\text { Ceramic floor, cotton fabric, synthetic fibers, eggcrate } \\
\text { foam mattress (with/without biological fluids) }\end{array}$ & 21 days & [9] \\
\hline & Office paper & $72 \mathrm{~h}$ to $>7$ days & {$[40]$} \\
\hline \multirow[t]{2}{*}{ E. coli } & Dry inanimate surfaces & $1.5 \mathrm{~h}$ to 16 months & [7] \\
\hline & Office paper & $<24 \mathrm{~h}$ & {$[40]$} \\
\hline \multirow[t]{2}{*}{ Klebsiella spp. } & Dry inanimate surfaces & $2 \mathrm{~h}$ to $>30$ months & {$[5,7]$} \\
\hline & $\begin{array}{l}\text { Ceramic floor, cotton fabric, synthetic fibers, eggcrate } \\
\text { foam mattress }\end{array}$ & $<14$ days & [9] \\
\hline Serratia marcescens & Dry inanimate surfaces & 3 days to 2 months & [7] \\
\hline \multirow[t]{2}{*}{ Pseudomonas aeruginosa } & Dry inanimate surfaces & $6 \mathrm{~h}$ to 16 months & {$[5,7,8]$} \\
\hline & Office paper & $72 \mathrm{~h}$ to $>7$ days & {$[40]$} \\
\hline \multirow[t]{3}{*}{ Clostridium difficile } & Dry inanimate surfaces (spores) & $>5$ months & {$[5,7,8]$} \\
\hline & Dry inanimate surfaces (vegetative form) & $15 \mathrm{~min}$ & [1] \\
\hline & Moist surfaces & $6 \mathrm{~h}$ & [1] \\
\hline Acinetobacter spp. & Dry inanimate surfaces & 3 days to 11 months & {$[5,7,8]$} \\
\hline Candida spp. & Dry inanimate surfaces & 3 days to $>4$ months & [7] \\
\hline Norovirus & Dry inanimate surfaces & $8 \mathrm{~h}$ to 2 weeks & {$[5,7,38]$} \\
\hline
\end{tabular}

(95\% confidence interval $[\mathrm{CI}], 1.65-2.77)$ for organism acquisition from prior room occupants [47].

In multiple nosocomial outbreaks, environmental contamination has been potentially associated with the transmission of the nosocomial pathogens [1, 5, 49-51]. It has been implicated in $11.6 \%$ of outbreaks when a source was identified [3]. Furthermore, observational studies have suggested that a contaminated environment may play a significant role in the transmission of unrecognized nosocomial pathogens during outbreaks and ongoing sporadic transmission $[2,3]$.

\section{Staphylococcus aureus}

SA is only second to $C$. difficile in causing HAIs [52]. Staphylococci have the ability to resist desiccation and persist up to 5 years on various surfaces in the environment and over a wide range of temperatures (Table 1). People are the primary reservoirs for SA, both methicillin-susceptible SA (MSSA) and MRSA, and approximately a third of US population is colonized, with nares bearing the highest burden [37]. Colonization increases risk of infection, and the majority SA infections are endogenously acquired. A carrier sheds SA variably into the surrounding environment, which can serve as a potential source of infection [37]. A higher nasal carriage burden correlates with greater environmental contamination [3]. Furthermore, a person who sheds excessively in the presence of an upper respiratory infection or exfoliative skin conditions, that is associated with airborne dispersal of SA, is referred to as "cloud adult" [37].

SA has been isolated from air and a variety of items, including stethoscopes, floors, charts, computer keyboards, door handles, tourniquets, pens, telephones, furniture, bed linen, patients' gowns, bedside table, and cellphones [22-24, 37]. Near-patient items had the highest degree of contamination [37]. Boyce et al. sampled environmental surfaces in rooms of patients colonized or infected with MRSA. Seventy-three percent of rooms of infected and $65 \%$ of rooms of colonized patients were contaminated [53]. Aerial dissemination of SA from contaminated bedding and clothing can deposit on surfaces [54]. In addition to person-to-person transmission, HCWs can acquire MRSA directly from patient contact or indirectly from contaminated environmental surfaces and transfer it to other patients. Direct patient contact with the contaminated environment also poses a risk [53]. In one study, $42 \%$ of HCWs who had no direct patient contact contaminated their gloves by touching contaminated surfaces [53]. There is also the risk of acquiring MRSA from a room previously occupied by a patient with MRSA $[2,55]$. SA has been 
commonly implicated in outbreaks. Gastmeier et al. analyzed 1022 nosocomial outbreaks, of which $14.8 \%$ were attributed to SA [56]. Outbreaks of MRSA due to environmental contamination have also been described [57].

\section{Vancomycin-Resistant Enterococcus}

VRE is one of the leading causes of nosocomial infections, commonly affecting debilitated hosts who have received multiple courses of antibiotics [58]. VRE has been known to survive for years (Table 1) in the hospital environment and is difficult to eradicate [2]. Enterococci have acquired the ability to resist desiccation and starvation and survive under harsh conditions, including exposure to solvents, detergents, antibiotics, and biocides [59]. Like SA, the principal reservoirs of VRE are colonized patients [12]. Symptomatic patients have higher rate of shedding compared to those who are colonized. However, if a patient is colonized at three or more body sites, environmental contamination can reach $70 \%$ in the occupied room [6].

High-touch surfaces, bedrails, doorknobs, bed linens, gowns, bedside tables, blood pressure cuffs, computer table, bedside tables, and various medical equipment, are more frequently contaminated [12]. In a recent microbiological study, VRE was the most commonly isolated MDRO in contaminated rooms [16]. Person-to-person transmission and exposure to contaminated HCW hands, contaminated surfaces, or equipment such as contaminated thermometers $[60,61]$ and electrocardiogram machines [62], and previously VRE contaminated room [63] are risk factors for VRE acquisition. Several VRE outbreaks in ICUs and hematology-oncology units related to environmental contamination have been reported [64, $65]$.

\section{Clostridium difficile}

C. difficile, a spore-forming anaerobe, is the most nosocomial pathogen that is responsible for $12.1 \%$ of HAIs [52]. C. difficile is in its vegetative form in the colon and sporulates in the environment under unfavorable conditions, which enables the organism to persist in the environment $[1,12]$. The vegetative form survives for a short period; whereas, spores are highly resistant to desiccation, heat, and disinfectants and can survive for months (Table 1). Approximately 3\% of healthy adults and 20 to $30 \%$ of hospitalized adults are colonized [1]. Colonized patients develop $C$. difficile infection (CDI) with antibiotic exposure that leads to alteration in the gut microbiome and proliferation of $C$. difficile. Although antibiotic use is the most commonly recognized risk factor for CDI, environmental contamination with spores is a known risk factor for $C$. difficile acquisition [1]. Symptomatic patients can shed up to $1 \times 10^{7} C$. difficile spores per gram of feces [66], resulting in widespread environmental contamination, ranging from 2.9 to $75 \%$ of surfaces [1]. Of note, asymptomatic patients shed spores and may also serve as a source for environmental contamination [1].

The environment of $C$. difficile patients has been shown quantitatively to contain a significantly higher spore count on the floor and the proximal environment compared with the environment of $C$. difficile-negative patients and wards. Furthermore, $C$. difficile has the capacity to disseminate to different geographical locations in the hospital [67]. C difficile has been recovered from HCW hands, telephone keypads, computers, doorknobs, pulse oximeter finger probes, medication carts, medication bar code scanners, mop pads, portable bed commode, electronic rectal thermometers, and sinks [1, 68, 69]. Fecal-oral transmission occurs in one of three ways: direct exposure to contaminated patient-care items and hightouch surfaces, direct transfer via contaminated hands, and indirect transfer through healthcare worker contact with the contaminated environment [1]. The most likely mechanism of exposure is via contaminated hands of HCWs [12]. During a CDI outbreak, environmental sampling of areas outside the $C$. difficile patient rooms, including physician work areas, nursing stations, $C$. difficile-negative patient rooms, and portable equipment, revealed $23 \%$ contamination rate [69]. Previously occupied rooms by $C$. difficile patients are a risk for transmission to subsequent occupants who come into contact with contaminated environmental surfaces. Airborne dissemination of $C$. difficile spores also contributes to its widespread environmental contamination $[54,66]$.

\section{Multi-Drug-Resistant Gram-Negative Organisms}

Gram-negative organisms have increasingly become an important cause of HAIs through contamination of water supplies and various surfaces.

Legionella spp. are gram-negative, intracellular organisms found in aquatic environments. They are one of several OPPPs detected at low levels in water distribution systems, including in healthcare facilities, cooling towers, air conditioning units, evaporative condensers, and distilled water [12]. Multiple factors contribute to its colonization and growth in the aqueous environment: stagnation, scale and sediment, free-living aquatic amoebas, including Acanthamoeba spp. and Hartmannella spp., that Legionella grow and amplify in; and a wide range of temperatures $[12,27]$. Legionella thrives at $35{ }^{\circ} \mathrm{C}$ but can multiple in 25 to $42{ }^{\circ} \mathrm{C}$. As mentioned previously, the organisms are found within amoebas and biofilms rather than in free-flowing water, making decontamination difficult [3, 12, 25, 27].

Legionella accounts for the majority of water-based infections in North America [3]. According to a CDC surveillance report, Legionella accounted for $66 \%$ of the 32 drinking water-associated outbreaks in healthcare facilities in 2011 to 2012 [70]. Although there are several species, Legionella 
pneumophila accounts for more than $90 \%$ of the infections [12]. Immunocompromised patients, the elderly, and smokers are at increased risk [12, 27]. Transmission occurs when contaminated water from showers, faucets, decorative fountains, cooling powers, humidifiers, and other water sources is aerosolized and inhaled or less commonly, aspirated [3, 12, 27]. Person-to-person transmission typically does not occur [25]. Contaminated aerosols generated by cooling towers, decorative fountains, showers, respiratory therapy equipment, humidifiers, and faucets have contributed to several hospital outbreaks $[2,12,28]$. Mechanisms to reduce water utilization such as electronic or hands-free faucets, which may promote favorable conditions for growth, have been shown to have higher Legionella contamination rates than manual faucets $[25,27]$. Legionella outbreak resulting from contaminated transesophageal echocardiography probes rinsed with unfiltered tap water has been reported [71]. Haupt et al. described laboratory-confirmed cases of Legionnaires disease in eight patients exposed to decorative fountain in the lobby of a hospital [34].

Acinetobacter is a ubiquitous opportunistic GN pathogen isolated from soil, water, animals, and humans and is a predominant cause of nosocomial infections and outbreaks in susceptible hosts, particularly in the ICUs [72-75]. Acinetobacter's propensity to cause outbreaks is facilitated by antimicrobial resistance and its ability to resist desiccation and survive for prolonged periods of time on multiple environmental surfaces $[1,73,76]$. Strains proliferate in moist environments and can survive for 5 to 11 months on dry surfaces and $60 \mathrm{~min}$ on fingertips (Table 1). Interestingly, up to $75 \%$ of hospitalized patients can become colonized with Acinetobacter spp. [77].

During outbreaks, Acinetobacter has been isolated from $\mathrm{HCW}$ hands, respiratory therapy equipment, food, tap water, infusion pumps, mattresses, pillows, bed curtains and blankets, bed rails, soap dispensers, bed, door handles, telephone receivers, tabletops, sink traps, and floors [1, 73, 77]. Acinetobacter is transmitted via contaminated hands, contact with contaminated surfaces or medical equipment, aspiration, and inhalation [12]. Potential for airborne transmission has been previously described [76, 78, 79]). Numerous Acinetobacter outbreaks have been associated with the presence of an extensive environmental contamination [1, 46, 73, 77]. Additionally, outbreak strains have the potential to become endemic within an institution [1]. A prospective cohort study conducted at a 656-bed tertiary care center examined environmental surfaces in ICU rooms of patients colonized or infected with Acinetobacter to determine which were most commonly contaminated. The study demonstrated that $48 \%$ sampled rooms were contaminated, and the most commonly contaminated surfaces were supply carts, floors, infusion pumps, and ventilator touch pads. Patient and environmental isolates were genetically similar in $85 \%$ of the cases [80].
Pseudomonas spp. are another important GN OPPPs associated with HAIs in ICUs and immunocompromised hosts, especially transplant, neutropenic, burn, and cystic fibrosis patients. Attributable morbidity and mortality is high in these populations due to intrinsic antimicrobial resistance [81]. Due to its inherent resistance to several disinfectants and ability to form biofilm and kill free-living amoeba that graze on environmental bacteria [81], Pseudomonas can survive up to 16 months (Table 1). The biofilm adheres to surfaces on sinks, sink traps, pipes, water lines, and hospital drains [2] and is able to withstand disinfection [81]. It has been found in tap and distilled water, respiratory therapy equipment, chlorhexidine, ultrasound gel, sinks, hydrotherapy pools, dialysis machines, eyewash stations, mouth swabs, and endoscopes [12, 82-84].

Transmission occurs through direct contact, aspiration and inhalation of water and water aerosols, and indirect transfer from moist environmental surfaces via contaminated hands [12]. Several Pseudomonas outbreaks associated with environmental contamination have been reported in medical and neonatal ICUs, and transplant and hematology-oncology units [85-88]. Knoester et al. described a prolonged outbreak of MDR Pseudomonas in an ICU attributed potentially to contaminated faucet aerators with indirect transfer to patients via contaminated HCW hands [89]. In a recent Pseudomonas outbreak in a neonatal ICU, unfiltered tap water was implicated as the source [90]. Also, damaged TEE probes used in cardiac surgeries have reportedly caused MDR Pseudomonas outbreak [84].

Enterobacterecieae, including those that are carbapenemresistant and ESBL-producers, are water-borne pathogens transmitted by fecally contaminated water or food [25]. It was widely believed that this group survives poorly on environmental surfaces compared to other nosocomial pathogens [1, 2]; however, studies have shown that E. coli and Klebsiella spp. may survive desiccation for more than a year and Serratia marcescens for several months (Table 1). Environmental sources and asymptomatic carriers are responsible for the majority of outbreaks [3]. Hospital sinks are common reservoirs for MDROs [28] and have been implicated in multiple outbreaks $[28,91,92]$.

\section{Nontuberculous Mycobacteria}

NTM or atypical mycobacteria are ubiquitous saprophytic and opportunistic pathogens that inhabit potable water. The ability of NTM to form biofilm on the interior surfaces of water pipes enables it to withstand chemical inactivation and provides a suitable environment for growth and proliferation [12]. NTM are highly resistant to chlorine, up to 100 times more resistant compared with coliforms, and can survive at varying temperatures [12]. M. xenopi can survive at $45{ }^{\circ} \mathrm{C}$, whereas M. kansasii, M. gordonae, M. fortuitum, and M. chelonae 
prefer colder environments and cannot endure such high temperatures [12].

These organisms are known to cause outbreaks and pseudo-outbreaks in the healthcare setting [3, 28]. Exposure and colonization occur through inhalation or aspiration, ingestion, or direct inoculation; and disease ensues in susceptible patients [12]. It is typically not transmitted person-to-person. Pseudo-outbreaks can occur when contaminated water or supplies are used during medical procedures or in the laboratory $[3,12]$. Outbreaks have been associated with contaminated waters in hot tubs, showers, dialysis machines, fountains, ice and ice machines, and hospital water supplies and disinfectant trays [3, 12, 28]. Cardiac and cosmetic surgeries, including liposuction and breast augmentation, are the most common surgeries associated with NTM infections. Mesotherapy and tattooing have also contributed to outbreaks [3, 12].

Rapidly growing NTM such as $M$. fortuitum and $M$. chelonae were almost exclusively responsible for the previously reported cardiac surgeries [36••]. However, the recent outbreaks in cardiac surgeries due contaminated HCU resulted from aerosolization of M. chimaera, a slow-growing NTM belonging to Mycobacterium-avium complex [35, 36••]. M. chimaera, an emerging pathogen causing prosthetic valve endocarditis (PVE), septicemia, and vascular graft infection with dissemination in cardiac patients, was first reported in 2013 in two patients who underwent prosthetic valve replacement in 2008 and 2010 at the Zurich Heart Center and subsequently developed PVE and septicemia, respectively, in 2011. A follow-up epidemiologic investigation revealed four additional cases who had undergone open cardiac surgeries involving implants between 2008 and 2012 [36••]. Common symptoms included fever, shortness of breath, fatigue, and weight loss with a median incubation period of 18 months [35]. Multiple environmental cultures, including water from HCU tanks and air sampling, were positive. The outbreak was traced to airborne transmission of contaminated water tanks in HCUs used with extracorporeal circulation during surgery. Shortly thereafter, multiple other cases were reported across Europe and internationally $[35,36]$.

\section{Fungal Organisms}

Invasive fungal infections have become an increasingly important cause of HAIs, causing significant morbidity and mortality in hospitalized and immunocompromised patients [14]. Candida spp. and Aspergillus spp. are the most prevalent sources of nosocomial fungal infections [14].

Candida spp. are the most common fungal pathogens causing HAIs, particularly in critically ill and immunocompromised patients. Candida's ability to form biofilm is important in its pathogenicity and persistence on surfaces [14]. C. albicans and $C$. grabrata can persist up to 4 and 5 months on surfaces, respectively (Table 1). Characteristics of specific
Candida spp. may influence the risk for exogenous transmission and nosocomial infections in certain patient populations [14, 93]. The most common pathogens, C. albicans, C. glabrata, C. tropicalis, C. parapsilosis, and C. krusei, account for $>90 \%$ of invasive disease [94]. Candida spp. have been isolated from the floor, countertops, and other inanimate surfaces in the hospital [14] and recovered from hands of HCWs [93]. Although most candidal infections are endogenous in origin, the source of infection may be acquired from the environment via the hands of HCWs, especially in critically ill patients $[14,93]$. Intravascular catheters have been responsible for most nosocomial outbreaks of Candida spp. [14], but contaminated infusates and biomedical devices have also been implicated in the transmission of Candida [93]. Person-to-person transmission has also been reported from geriatric short-stay units [95].

First described in Japan after isolation from an ear canal in 2009 [96], C. auris has since caused multiple nosocomial outbreaks worldwide $[97-99,100 \bullet \cdot$. It is phylogenetically related to the $C$. haemulonii complex and difficult to identify in the lab. Similar to other Candida species, C. auris is a nosocomial pathogen effecting vulnerable hosts with serious underlying conditions. It is highly multidrug-resistant, particularly to the azoles, and is associated with high mortality [97, 99, 100••]. Environmental sampling from various surfaces, including mattress, bedside table, bed rail, chair, floor, equipment monitors and key pads, windowsills and air, were positive for $C$. auris $[99,100 \cdot \bullet$ up to 3 months after initial infection $[100 \bullet \bullet$. Horizontal transmission among susceptible patients was described $[97,99]$. Contaminated surfaces have been implicated as a potential source of dissemination [99]. Schelenz et al. described an ongoing $C$. auris outbreak among 50 patients over a 16 -month period that was attributed to low level environmental contamination [99].

Aspergillus spp. are ubiquitous opportunistic molds found widely in the environment and exposure to airborne spores occurs frequently, especially near decaying organic matter. The spores of Aspergillus spp. resist drying, are only a couple microns in size, and can remain airborne indefinitely [12]. Exposure to airborne fungal pathogens such as Aspergillus spp. within the hospital environment, especially during construction, renovation, demolition or excavation, has caused nosocomial outbreaks, especially in units with high-risk patients [101]. Although the most common source of nosocomial Aspergillus infection is contaminated air, it has also been recovered from the hospital water supply and plumbing systems $[28,102]$. The role of the contaminated water with Aspergillus as the source of HAIs is still unclear [101]. The highest airborne Aspergillus spore counts were detected in patient's bathrooms, suggesting possible aerosolization of Aspergillus spores from the shower facilities [102]. Vehicles of transmission include improperly functioning ventilation systems, poorly maintained air filters, damp wood building 
material, construction within and around the hospital, water leaks, food, and ornamental plants [12]. Contaminated dressings used for wounds and to secure arm boards have resulted in cutaneous aspergillosis [103, 104]. Aspergillus outbreaks have been also attributed to natural disasters such as flooding [29].

\section{Norovirus}

Noroviruses are a group of non-enveloped, single-stranded icosahedral RNA viruses that belong to the family Caliciviridae and are the most common cause of viral gastroenteritis in humans [1]. The capsid structure enables it to withstand a wide range of temperatures and chemical disinfection, prolonging its survival $[1,105]$. Norovirus can survive up to a week on environmental surfaces, 10 days in various foods and a couple months in water (Table 1). Several microbiologic and epidemiologic features contribute to its ability to cause outbreaks in various settings, including hospitals and nursing homes $[1,2]$. Norovirus requires a very low inoculating dose, is highly infective with a high attack rate, has prolonged shedding, is stable in the environment, and has numerous modes of transmission [1].

Norovirus has been isolated from high-touch surfaces such as toilet taps, door handles, hospital equipment, elevator, and microwave buttons, switches, and telephones [15]. Studies have demonstrated the transfer of norovirus from contaminated fingers to various surfaces, in particular toilet tops, door handles, and telephone receivers [1]. Norovirus can be transmitted directly from contact with an infected person via fecaloral route, indirectly through contact with contaminated surfaces or objects, and by consumption of fecally contaminated food or water [1]. Aerosolized vomit contaminating surfaces or being swallowed after entering the oral mucosa has also been implicated in transmission [1]. Healthcare-associated norovirus outbreaks have recently become more common [105], and widespread environmental contamination, including areas outside of the infected patient's room, contribute to its propagation [1]. Sudden and widespread outbreaks are common and infect unsuspecting patients and HCWs [15, 105]. More than a fourth of the norovirus outbreaks occur in hospitals and long-term care facilities based on reported studies [1]. Wu et al. described a prolonged norovirus outbreak in long-term care facility among at least half of the patients and HCWs as a result of extensive environmental contamination [105].

\section{Conclusion}

Over the past couple decades, there has been increasing evidence linking environmental contamination to the acquisition of nosocomial pathogens and HAIs, potentially leading to outbreaks and ongoing sporadic transmission. Several pathogens can persist in the environment for prolonged periods. Environmental surfaces and objects may serve as reservoirs for these nosocomial pathogens that can be transmitted by the hands of HCWs to patients, as a result of inadequate hand hygiene. However, reinforcing appropriate hand hygiene and strengthening cleaning/disinfection protocols can interrupt this transmission and, therefore, are essentials for the prevention and control of HAIs.

\section{Compliance with Ethical Standards}

Conflict of Interest Geehan Suleyman, George Alangaden, and Ana Cecilia Bardossy declare that they have no conflict of interest.

Human and Animal Rights and Informed Consent This article does not contain any studies with human or animal subjects performed by any of the authors.

\section{References}

Papers of particular interest, published recently, have been highlighted as:

- Of importance

- Of major importance.

1. Weber DJ, Rutala WA, Miller MB, Huslage K, Sickbert-Bennett E. Role of hospital surfaces in the transmission of emerging health care-associated pathogens: Norovirus, Clostridium difficile, and Acinetobacter species. Am J Infect Control 2010;38(5 Suppl 1): S25-S33.

2. Dancer SJ. Controlling hospital-acquired infection: focus on the role of the environment and new technologies for decontamination. Clin Microbiol Rev. 2014;27(4):665-90.

3. Sood G, Perl TM. Outbreaks in health care settings. Infect Dis Clin N Am. 2016;30(3):661-87.

4. Huslage K, Rutala WA, Sickbert-Bennett E, Weber DJ. A quantitative approach to defining "high-touch" surfaces in hospitals. Infect Control Hosp Epidemiol. 2010;31(8):850-3.

5. Otter JA, Yezli S, Salkeld JA, French GL. Evidence that contaminated surfaces contribute to the transmission of hospital pathogens and an overview of strategies to address contaminated surfaces in hospital settings. Am J Infect Control. 2013;41(5 Suppl): S6-11.

6. Boyce JM. Environmental contamination makes an important contribution to hospital infection. J Hosp Infect. 2007;65(Suppl 2):50-4.

7. Kramer A, Schewebke I, Kampf G. How long do nosocomial pathogens persist on inanimate surfaces? A systematic review. BMC Infect Dis. 2006;6:130.

8. Chemaly RF, Simmons S, Dale C, Ghantoji SS, Rodriguez M, Gubb J, et al. The role of the healthcare environment in the spread of multidrug-resistant organisms: update on current best practices for containment. Ther Adv Infect Dis. 2014;2(3-4):79-90.

9. Esteves DC, Pereira VC, Souza JM, Keller R, Simões RD, Winkelstroter Eller LK, et al. Influence of biological fluids in bacterial viability on different hospital surfaces and fomites. Am J Infect Control. 2016;44(3):311-4. 
10. "Environment of Care." Comprehensive Accreditation Manual for Ambulatory Care (CAMAC). https://foh.psc.gov/tjc/ environmentofcare.html. Accessed November 2, 2017.

11. PIDAC. Best practices for environmental cleaning for prevention and control of infections 2012. https://www.publichealthontario. $\mathrm{ca} /$ en/BrowseByTopic/InfectiousDiseases/PIDAC/Pages/ PIDAC Documents.aspx. Accessed October 1, 2017.

12. Sehulster L, Chinn RY. CDC; HICPAC. Guidelines for environmental infection control in health-care facilities: recommendations of the CDC and the Healthcare Infection Control Practices Advisory Committee (HICPAC). MMWR Morb Mortal Wkly Rep. 2003;52(RR-10):1-42.

13. Olmsted RN. Prevention by design: construction and renovation of health care facilities for patient safety and infection prevention. Infect Dis Clin N Am. 2016;30(3):713-28.

14. Suleyman G, Alangaden GJ. Nosocomial fungal infections: epidemiology, infection control, and prevention. Infect Dis Clin North Am. 2016;30(4):1023-52.

15. Dancer SJ. The role of environmental cleaning in the control of hospital-acquired infection. J Hosp Infect. 2009;73(4):378-85.

16. Shams AM, Rose LJ, Edwards JR, Cali S, Harris AD, Jacob JT, et al. Assessment of the overall and multidrug-resistant organism bioburden on environmental surfaces in healthcare facilities. Infect Control Hosp Epidemiol. 2016;37(12):1426-32.

17. Patel PK, Mantey J, Mody L. Patient hand colonization with MDROs is associated with environmental contamination in postacute care. Infect Control Hosp Epidemiol. 2017;38(9):1110-3.

18. Barnes SL, Morgan DJ, Harris AD, Carling PC, Thom KA. Preventing the transmission of multidrug-resistant organisms: modeling the relative importance of hand hygiene and environmental cleaning interventions. Infect Control Hosp Epidemiol. 2014;35(9):1156-62.

19. Deshpande A, Cadnum JL, Fertelli D, Sitzlar B, Thota P, Mana TS, et al. Are hospital floors an underappreciated reservoir for transmission of health care-associated pathogens? Am J Infect Control. 2017;45(3):336-8. This study shows that the floors in patients' rooms are contaminated with healthcare-associated microorganisms that be indirectly transferred between the fomites in contact with the floor and HCW hands

20. Koganti S, Alhmidi H, Tomas ME, Cadnum JL, Jencson A, Donskey CJ. Evaluation of hospital floors as a potential source of pathogen dissemination using a nonpathogenic virus as a surrogate marker. Infect Control Hosp Epidemiol. 2016;37(11): 1374-7.

21. O'Flaherty N, Fenelon L. The stethoscope and healthcareassociated infection: a snake in the grass or innocent bystander? J Hosp Infect. 2015;91(1):1-7.

22. Brady RR, Verran J, Damani NN, Gibb AP. Review of mobile communication devices as potential reservoirs of nosocomial pathogens. J Hosp Infect. 2009;71(4):295-300.

23. Kanayama AK, Takahashi H, Yoshizawa S, Tateda K, Kaneko A, Kobayashi I. Staphylococcus aureus surface contamination of mobile phones and presence of genetically identical strains on the hands of nursing personnel. Am J Infect Control. 2017;45(8): 929-31.

24. Chen KH, Chen LR, Wang YK. Contamination of medical charts: an important source of potential infection in hospitals. PLoS One. 2014;9(2):e78512.

25. Gamage SD, Ambrose M, Kralovic SM, Roselle GA. Water safety and Legionella in health care: Priorities, policy, and practice. Infect Dis Clin North Am. 2016;30(3):689-712.

26. Stojek NM, Szymanska J, Dutkiewicz J. Gram-negative bacteria in water distribution systems of hospitals. Ann Agric Environ Med. 2008;15(1):135-42.

27. Decker BK, Palmore TN. The role of water in healthcareassociated infections. Curr Opin Infect Dis. 2013;26(4):345-51.
28. Kanamori H, Weber DJ, Rutala WA. Healthcare outbreaks associated with a water reservoir and infection prevention strategies. Clin Infect Dis. 2016;62(11):1423-35.

29. Apisarnthanarak A, Warren DK, Mayhall CG. Healthcareassociated infections and their prevention after extensive flooding. Curr Opin Infect Dis. 2013;26(4):359-65.

30. Halabi M, Wiesholzer-Pittl M, Schoberl J, Mittermayer H. Nontouch fittings in hospitals: a possible source of Pseudomonas aeruginosa and Legionella spp. J Hosp Infect. 2001;49:117-21.

31. Merrer J, Girou E, Ducellier D, Clavreul N, Cizeau F, Legrand P, et al. Should electronic faucets be used in intensive care and hematology units? Intensive Care Med. 2005;31(12):1715-8.

32. Sydnor ER, Bova G, Gimburg A, Cosgrove SE, Perl TM, Maragakis LL. Electronic-eye faucets: Legionella species contamination in healthcare settings. Infect Control Hosp Epidemiol. 2012;33(3):235-40.

33. Palmore T, Stock F, White M, Bordner M, Michelin A, Bennett JE, et al. A cluster of cases of nosocomial Legionnaires disease linked to a contaminated hospital decorative water fountain. Infect Control Hosp Epidemiol. 2009;30(8):764-76.

34. Haupt TE, Heffernan RT, Kazmierczak JJ, Nehls-Lowe H, Rheineck B, Powell C, et al. An outbreak of Legionnaires disease associated with a decorative water wall fountain in a hospital. Infect Control Hosp Epidemiol. 2012;33(2):185-91.

35. Kohler P, Kuster SP, Bloemberg G, Schulthess B, Frank M, Tanner FC, et al. Healthcare-associated prosthetic heart valve, aortic vascular graft, and disseminated Mycobacterium chimaera infections subsequent to open heart surgery. Eur Heart J. 2015;36:2745-53.

36.• Sax H, Bloemberg G, Hasse B, Sommerstein R, Kohler P, Achermann Y, et al. Prolonged outbreak of Mycobacterium chimaera infection after open-chest heart surgery. Clin Infect Dis. 2015;61(1):67-75. This paper describes the first outbreak investigation of Mycobacterium chimaera infections following open-heart surgery at a European hospital.

37. Dancer SJ. Importance of the environment in methicillin-resistant Staphylococcus aureus acquisition: the case for hospital cleaning. Lancet Infect Dis. 2008;8(2):101-13.

38. Kok J. Surfaces and fomites as a source of healthcare-associated infections. Microbiol Austr. 2014;35:24-5.

39. Rossi D, Devienne KF, Raddi MSG. Influencia de fluidos biologicos na sobrevivencia de Staphylococcus aureus sobre diferentes superficies secas. Rev Cienc Farm Basica Appl. 2008;29:211-4.

40. Hübner NO1, Hübner C, Kramer A, Assadian O. Survival of bacterial pathogens on paper and bacterial retrieval from paper to hands: preliminary results. Am J Nurs. 2011;111(12):30-4.

41. Zarpellon MN, Gales AC, Sasaki AL, Selhorst GJ, Menegucci TC, Cardoso CL, et al. Survival of vancomycin-intermediate Staphylococcus aureus on hospital surfaces. J Hosp Infect. 2015;90(4):347-50.

42. Wagenvoort JH, De Brauwer EI, Penders RJ, Willems RJ, Top J, Bonten MJ. Environmental survival of vancomycin-resistant Enterococcus faecium. J Hosp Infect. 2011;77(3):282-3.

43. Wagenvoort JH, De Brauwer EI, Penders RJ, van der Linden CJ, Willems RJ, Top J, et al. Environmental survival of vancomycinsensitive ampicillin-resistant Enterococcus faecium (AREfm). Eur J Clin Microbiol Infect Dis. 2015;34(9):1901-3.

44. Hu H, Johani K, Gosbell IB, Jacombs AS, Almatroudi A, Whiteley GS, et al. Intensive care unit environmental surfaces are contaminated by multidrug-resistant bacteria in biofilms: combined results of conventional culture, pyrosequencing, scanning electron microscopy, and confocal laser microscopy. J Hosp Infect. 2015;91(1):35-44.

45. Hota B. Contamination, disinfection, and cross-colonization: are hospital surfaces reservoirs for nosocomial infection? Clin Infect Dis. 2004;39(8):1182-9. 
46. Otter JA, Yezli S, French GL. The role played by contaminated surfaces in the transmission of nosocomial pathogens. Infect Control Hosp Epidemiol. 2011;32(7):687-99.

47. Mitchell BG, Dancer SJ, Anderson M, Dehn E. Risk of organism acquisition from prior room occupants: a systematic review and meta-analysis. J Hosp Infect. 2015;91(3):211-7.

48. Nseir S, Blazejewski C, Lubret R, Wallet F, Courcol R, Durocher A. Risk of acquiring multidrug-resistant Gram-negative bacilli from prior room occupants in the intensive care unit. Clin Microbiol Infect. 2011;17(8):1201-8.

49. Hota B. Contamination, disinfection, and cross-colonization: are hospital surfaces reservoirs for nosocomial infection? Clin Infect Dis. 2004;39(8):1182-9.

50. Weber DJ, Anderson D, Rutala WA. The role of the surface environment in healthcare-associated infections. Curr Opin Infect Dis. 2013;26(4):338-44.

51. Boyce JM. Environmental contamination makes an important contribution to hospital infection. J Hosp Infect. 2007 Jun;65(Suppl 2):50-4.

52. Magill SS, Edwards JR, Bamberg W, Beldavs ZG, Dumyati G, Kainer MA, et al. Multistate point-prevalence survey of health care-associated infections. N Engl J Med. 2014;370(13):1198208.

53. Boyce JM, Potter-Bynoe G, Chenevert C, King T. Environmental contamination due to methicillin-resistant Staphylococcus aureus: possible infection control implications. Infect Control Hosp Epidemiol. 1997;18(9):622-7.

54. Beggs C, Knibbs LD, Johnson GR, Morawska L. Environmental contamination and hospital-acquired infection: factors that are easily overlooked. Indoor Air. 2015;25(5):462-74.

55. Carling PC. Optimizing health care environmental hygiene. Infect Dis Clin N Am. 2016;30(3):639-60.

56. Gastmeier P, Stamm-Balderjahn S, Hansen S, Nitzschke-Tiemann F, Zuschneid I, Groneberg K, et al. How outbreaks can contribute to prevention of nosocomial infection: analysis of 1,022 outbreaks. Infect Control Hosp Epidemiol. 2005;26(4):357-61.

57. Rampling A, Wiseman S, Davis L, Hyett AP, Walbridge AN, Payne GC, et al. Evidence that hospital hygiene is important in the control of methicillin-resistant Staphylococcus aureus. J Hosp Infect. 2001;49(2):109-16.

58. Suleyman G, Mahan M, Zervos MJ. Comparison of Daptomycin and Linezolid in the treatment of vancomycin-resistant Enterococcus faecium in the absence of endocarditis. Infect Dis Clin Pract. 2017;25(3):151-4.

59. Lebreton F, Manson AL, Saavedra JT, Straub TJ, Earl AM, Gilmore MS. Tracing the Enterococci from Paleozoic origins to the hospital. Cell. 2017;169(5):849-61.

60. Livornese LL, Dias S, Samel C, Romanowski B, Taylor S, May P, et al. Hospital-acquired infection with vancomycin-resistant Enterococcus faecium transmitted by electronic thermometers. Ann Intern Med. 1992;117:112 116.

61. Porwancher R, Sheth A, Remphrey S, Taylor E, Hinkle C, Zervos M. Epidemiological study of hospital-acquired infection with vancomycin-resistant Enterococcus faecium: possible transmission by an electronic ear-probe thermometer. Infect Control Hosp Epidemiol. 1997;18(11):771-3.

62. Falk PS, Winnike J, Woodmansee C, Desai M, Mayhall CG. Outbreak of vancomycin-resistant enterococci in a burn unit. Infect Control Hosp Epidemiol. 2000;21(9):575 582.

63. Drees M, Snydman DR, Schmid CH, Barefoot L, Hansjosten K, Vue PM, et al. Prior environmental contamination increases the risk of acquisition of vancomycin-resistant enterococci. Clin Infect Dis. 2008;46(5):678-85.

64. Sample ML, Gravel D, Oxley C, Toye B, Garber G, Ramotar K. An outbreak of vancomycin-resistant enterococci in a hematology-oncology unit: control by patient cohorting and terminal cleaning of the environment. Infect Control Hosp Epidemiol. 2002;23(8):468-70.

65. Yoon YK, Sim HS, Kim JY, Park DW, Sohn JW, Roh KH, et al. Epidemiology and control of an outbreak of vancomycin-resistant enterococci in the intensive care units. Yonsei Med J. 2009;50(5): 637-43.

66. Best EL, Fawley WN, Parnell P, Wilcox MH. The potential for airborne dispersal of Clostridium difficile from symptomatic patients. Clin Infect Dis. 2010;50(11):1450-7.

67. Mutters R, Nonnenmacher C, Susin C, Albrecht U, Kropatsch R, Schumacher S. Quantitative detection of Clostridium difficile in hospital environmental samples by real-time polymerase chain reaction. J Hosp Infect. 2009;71(1):43-8.

68. Sooklal S, Khan A, Kannangara S. Hospital Clostridium difficile outbreak linked to laundry machine malfunction. Am J Infect Control. 2014;42(6):674-5.

69. Dumford DM III, Nerandzic MM, Eckstein BC, Donskey CJ. What is on that keyboard? Detecting hidden environmental reservoirs of Clostridium difficile during an outbreak associated with North American pulsed-field gel electrophoresis type 1 strains. Am J Infect Control. 2009;37(1):15-9.

70. Beer KD, Gargano JW, Roberts VA, Hill VR, Garrison LE, Kutty PK, et al. Surveillance for waterborne disease outbreaks associated with drinking water-United States, 2011-2012. MMWR Morb Mortal Wkly Rep. 2015;64(31):842-8.

71. Levy PY, Teysseire N, Etienne J, Raoult D. A nosocomial outbreak of Legionella pneumophila caused by contaminated transesophageal echocardiography probes. Infect Control Hosp Epidemiol. 2003;24:619-22.

72. Dettori M, Piana A, Deriu MG, Lo Curto P, Cossu A, Musumeci $\mathrm{R}$, et al. Outbreak of multidrug-resistant Acinetobacter baumannii in an intensive care unit. New Microbiol. 2014;37(2):185-91.

73. Fournier PE, Richet H. The epidemiology and control of Acinetobacter baumannii in health care facilities. Clin Infect Dis. 2006;42(5):692-9.

74. Maragakis LL, Cosgrove SE, Song X, Kim D, Rosenbaum P, Ciesla N, et al. An outbreak of multidrug-resistant Acinetobacter baumannii associated with pulsatile lavage wound treatment. JAMA. 2004;292(24):3006-11.

75. Villegas MV, Hartstein AI. Acinetobacter outbreaks, 1977-2000. Infect Control Hosp Epidemiol. 2003;24(4):284-95.

76. Shimose LA, Masuda E, Sfeir M, Berbel Caban A, Bueno MX, dePascale D, et al. Carbapenem-resistant Acinetobacter baumannii: concomitant contamination of air and environmental surfaces. Infect Control Hosp Epidemiol. 2016;37(7):777-81.

77. Manchanda V, Sanchaita S, NP Singh. Multidrug resistant Acinetobacter. J Glob Infect Dis 2010; 2(3):291-304.

78. Gao J, Zhao X, Bao Y, Ma R, Zhou Y, Li X, et al. Antibiotic resistance and OXA type carbapenemases-encoding genes in airborne Acinetobacter baumannii isolated from burn wards. Burns. 2014;40(2):295-9.

79. Munoz-Price LS, Fajardo-Aquino Y, Arheart KL, Cleary T, DePascale D, Pizano L, et al. Aerosolization of Acinetobacter baumannii in a trauma ICU. Crit Care Med. 2013;41(8):1915-8.

80. Thom KA, Johnson JK, Lee MS, Harris AD. Environmental contamination because of multidrug-resistant Acinetobacter baumannii surrounding colonized or infected patients. Am J Infect Control. 2011;39(9):711-5.

81. Kerr KG, Snelling AM. Pseudomonas aeruginosa: a formidable and ever-present adversary. J Hosp Infect. 2009;73(4):338-44.

82. Iversen BG, Jacobsen T, Eriksen HM, Bukholm G, Melby KK, Nygård K, et al. An outbreak of Pseudomonas aeruginosa infection caused by contaminated mouth swabs. Clin Infect Dis. 2007;44(6):794-801. 
83. Weber DJ, Rutala WA, Sickbert-Bennett EE. Outbreaks associated with contaminated antiseptics and disinfectants. Antimicrob Agents Chemother. 2007;51(12):4217-24.

84. Seki M, Machida H, Yamagishi Y, Yoshida H, Tomono K. Nosocomial outbreak of multidrug-resistant Pseudomonas aeruginosa caused by damaged transesophageal echocardiogram probe used in cardiovascular surgical operations. J Infect Chemother. 2013;19:677-81.

85. Eckmanns T, Oppert M, Martin M, Amorosa R, Zuschneid I, Frei U, et al. An outbreak of hospital-acquired Pseudomonas aeruginosa infection caused by contaminated bottled water in intensive care units. Clin Microbiol Infect. 2008;14(5):454-8.

86. Engelhart S, Krizek L, Glasmacher A, Fischnaller E, Marklein G, Exner M. Pseudomonas aeruginosa outbreak in a haematologyoncology unit associated with contaminated surface cleaning equipment. J Hosp Infect. 2002;52(2):93-8.

87. Hota S, Hirji Z, Stockton K, Lemieux C, Dedier H, Wolfaardt G, et al. Outbreak of multidrug-resistant Pseudomonas aeruginosa colonization and infection secondary to imperfect intensive care unit room design. Infect Control Hosp Epidemiol. 2009;30:25-33.

88. Jefferies JM, Cooper T, Yam T, Clarke SC. Pseudomonas aeruginosa outbreaks in the neonatal intensive care unit-a systematic review of risk factors and environmental sources. J Med Microbiol. 2012;61(Pt 8):1052-61.

89. Knoester M, de Boer MG, Maarleveld JJ, Claas EC, Bernards AT, de Jonge E, et al. An integrated approach to control a prolonged outbreak of multidrug-resistant Pseudomonas aeruginosa in an intensive care unit. Clin Microbiol Infect. 2014;20(4):O207-15.

90. Kinsey CB, Koirala S, Solomon B, Rosenberg J, Robinson BF, Neri A, et al. Pseudomonas aeruginosa outbreak in a neonatal intensive care unit attributed to hospital tap water. Infect Control Hosp Epidemiol. 2017;38(7):801-8.

91. Kotsanas D, Wijesooriya WR, Korman TM, Gillespie EE, Wright L, Snook K, et al. "Down the drain": carbapenem-resistant bacteria in intensive care unit patients and handwashing sinks. Med J Aust. 2013;198(5):267-9.

92. Lowe C, Willey B, O'Shaughnessy A, Lee W, Lum M, Pike K, et al. Outbreak of extended-spectrum $\beta$-lactamase-producing Klebsiella oxytoca infections associated with contaminated handwashing sinks. Emerg Infect Dis. 2012;18(8):1242-7.

93. Pfaller MA. Nosocomial candidiasis: emerging species, reservoirs, and modes of transmission. Clin Infect Dis. 1996;22(Suppl 2): S89-94.

94. Pappas PG, Kauffman CA, Andes DR. Clinical practice guideline for the management of candiadiasis: 2016 update by the Infectious Diseases Society of America. Clin Infect Dis. 2016;62(4):e1-e50.
95. Fanello S, Bouchara JP, Jousset N, Delbos V, LeFlohic AM. Nosocomial Candida albicans acquisition in a geriatric unit: epidemiology and evidence for person-to-person transmission. $\mathrm{J}$ Hosp Infect. 2001;47(1):46-52.

96. Satoh K, Makimura K, Hasumi Y, Nishiyama Y, Uchida K, Yamaguchi H. Candida auris sp. nov., a novel ascomycetous yeast isolated from the external ear canal of an inpatient in a Japanese hospital. Microbiol Immunol. 2009;53(1):41-4.

97. Calvo B, Melo ASA, Perozo-Mena A, Hernandez M, Francisco EC, Hagen F, et al. First report of Candida auris in America: clinical and microbiological aspects of 18 episodes of candidemia. J Inf Secur. 2016;73(4):369-74.

98. Magobo RE, Corcoran C, Seetharam S, Govender NP. Candida auris-associated candidemia, South Africa. Emerg Infect Dis. 2014;20(7):1250-1.

99. Schelenz S, Hagen F, Rhodes JL, Abdolrasouli A, Chowdhary A, Hall A, et al. First hospital outbreak of the globally emerging Candida auris in a European hospital. Antimicrob Resist Infect Control 2016;5:35.

100.• Vallabhaneni S, Kallen A, Tsay S, Chow N, Welsh R, Kerins J, et al. Investigation of the first seven reported cases of Candida auris, a globally emerging invasive, multidrug-resistant fungusUnited States, May 2013-August 2016. Am J Transplant 2017;17(1):296-299. This is the first study that describes the recent $C$. auris outbreak in the USA and its implications for public health.

101. Kanamori H, Rutala WA, Sickbert-Bennett EE, Weber DJ. Review of fungal outbreaks and infection prevention in healthcare settings during construction and renovation. Clin Infect Dis. 2015;61(3): 433-44.

102. Anaissie EJ, Stratton SL, Dignani MC, Lee CK, Summerbell RC, Rex JH, et al. Pathogenic molds (including Aspergillus species) in hospital water distribution systems: a 3-year prospective study and clinical implications for patients with hematologic malignancies. Blood. 2003;101(7):2542-6.

103. Bryce EA, Walker M, Scharf S, Lim AT, Walsh A, Sharp N, et al. An outbreak of cutaneous aspergillosis in a tertiary-care hospital. Infect Control Hosp Epidemiol. 1996;17(3):170-2.

104. McCarty JM, Flam MS, Pullen G, Jones R, Kassel SH. Outbreak of primary cutaneous aspergillosis related to intravenous arm boards. J Pediatr. 1986;108(5 Pt 1):721-4.

105. Wu HM, Fornek M, Schwab KJ, Chapin AR, Gibson K, Schwab E, et al. A norovirus outbreak at a long-term-care facility: the role of environmental surface contamination. Infect Control Hosp Epidemiol. 2005;26(10):802-10. 